\title{
A Business Process Modelling Approach to Communication Management in Projects
}

\author{
Michał Kuciapski \\ University of Gdansk, Department of Business Informatics, Sopot, Poland \\ m.kuciapski@ug.edu.pl
}

\begin{abstract}
Evolution in business processes, information systems and modelling notations has resulted in the development of modern modelling languages, such as BPMN or UML. In elaborated notations it could be noticed that there is a high concentration on the activities of processes with the lack or insufficient integration of many important management categories such as communication, quality or risk. This indicates that it is still necessary to further improve modelling approaches. As presented in the literature, especially a systematic approach to communication management is crucial to enable organizations to successfully carry out their projects. Thus, modelling notations should take into account communication management-related features. The main objective of the article is to propose a modelling notation for communication management of business and project processes that would enable better communication between relevant parties. It begins by introducing the current state of modelling notations. The introduction is a starting point for the second section, which contains a presentation of an elaborated communication management notation for business and project processes as a separate diagram type. The next part of the paper shows the verification of this elaborated modelling approach. The article concludes with a summary.
\end{abstract}

Keywords: Communication management, project management, business process modelling notation, business process modelling.

\section{Introduction}

A continuous and decades-long evolution of all-purpose and domain-centric notations resulted in the creation of modern modelling standards, such as Unified Modelling Language (UML), Business Process Modelling Notation (BPMN) or the Business Process Modelling System (BPMS) method, which was integrated in the ADONIS business management solution "in order to use a semi-formal description of business process models" [26]. There is, however, plenty of room for further business process modelling improvement. Needless to say, a few BPMN extensions were proposed by both the academic community and the business modelling community, such as interaction modelling as iBPMN [3], collaborative e-business process modelling [7], data representation specification [18] or manufacturing domain modelling [28]. 
Moreover, in many situations the organizations themselves leave the methodological and notational aspects to the contractor [27], even though some methodologies predate the notion of process modelling or are niche in character.

The first efforts to unify visual modelling techniques were conducted by the OMG (Object Management Group) consortium [4]. Their research and design was concentrated on the development of UML in the field of business process modelling [1], [5]. UML was designed as a standard for general modelling use. A modern approach considered to be a major candidate for wide adoption has been BPMN [6], which, unlike UML, has a very specialized character dedicated to business process modelling. Although UML and BPMN are considered to be the most popular modelling languages [21], there are also other important approaches. An example of such a widely practiced approach is IDEF (Integration Definition Methods) [13]. Another visual modelling approach worth listing is ARIS (Architecture of Integrated Information Systems) due to its integration by SAP company into the SAP R/3 ERP system [25]. It is also necessary to highlight BPMS, which is implemented by BOC into ADONIS business process management software.

All of the above-mentioned modelling notations concentrate on modelling processes as a flow of activities with distinguishing decision-making aspects. Some integrate notations allow modelling the document flow (UML and BPMS), workflow (BPMS), and collaboration management (BPMN), but they still do not take into account important management categories as distinguished by the PMI (Project Management Institute), such as: scope, time, costs, quality, control, risk, communication (collaboration in BPMN) or procurement [2]. These are all especially important in processes related to project management. The integration of risk management into notation in BPMS and UML shows that organizations responsible for business process modelling are aware of current notation restrictions.

Risk, quality and communication management are considered to be the key aspects of project management [16]. According to the Bull Survey, the major cause of project failure is: "bad communication between relevant parties" [9]. In 57\% of the projects analysed, weak or improper communication management was identified as the main failure criterion. Other important elements listed in the report that have had a great impact on unsuccessful initiatives are a lack of planning, i.e., a lack of scheduling resources and activities (39\%), and poor quality control (35\%) [9], [20].

Quality and risk management modelling has been presented in separate articles as an appropriate modelling approach [15], [12]. Risk management has also been enclosed in the form of an extension for modern notations like BPMN and BPMS [13].

BPMN contains a diagram related to communication management [10] that is for designing collaboration management. In this field there is an available notation for the message flow or conversations. The author's practical project management experience and BPMN collaboration modelling allow specifying a number of restrictions of such an approach:

- on a single diagram there are included both activities and communication management, even when activities are not connected with communication; 
- it does not include the notation for defining communication: channels, results, requirements for starting (for example, documents), responsible role for coordination;

- it presents participants as tracks; thus, it is difficult to design multiplayer collaboration for actions;

- as it includes, apart from communication aspects, also the flow of activities and decisions, even in the situations of intermediate complexity there is a need to design very complex diagrams [11].

Indicated aspects of BPMN point its difficulty for the application to communication management modelling. Another much simpler approach to use in comparison with BPMN is RACI Charts [8]. It allows for fast and precise ascription of roles to tasks. It may be treated as part of communication management since diagrams show which roles have to cooperate during activities. It concentrates on responsibilities without inclusion of connections between activities and, thus, communication flow. Also similar to BPMN communication is omitted: channels, results, requirements for starting (for example, documents), responsible role for coordination. Thus, RACI diagrams are not complex enough for effective communication management in projects.

The factors listed above, together with the Bull Survey results indicate the importance of proper, systematic and unified communication management of business and project processes [9] also with appropriate support from a modelling notation in designing the specifications of processes. Thus, the main objective of the paper is to propose a modelling approach and notation for communication management in business and project processes that has a positive impact on efficiency of their implementation with a suitable level of complexity. The author's practical project management experience o shows that the lack of integrating complex specifications of communication management has a negative impact on this aspect of project management and often indirectly has a strong influence on cursory quality management in projects [24].

\section{Modelling Approach to Managing Communication in Processes}

An approach used for managing communication in projects or business processes with a strong emphasis on its integration with those models of processes should be an important element for eliminating failures that occur due to improper communication between the relevant parties. A proper original notation has been elaborated based on the author's project management experience and the analysis results of approaches that are related to communication management, such as BPMN (collaboration diagrams) and RACI Charts presented in the first section of the article.

As a key element of communication management modelling, the models were assumed to include specifications of processes. In order to achieve such a result, 
correct stereotypes for business and project process diagrams were elaborated for various management categories ${ }^{1}$ as presented in Table 1.

Table 1. Notation Stereotypes Used to Identify Management Categories

\begin{tabular}{ll} 
Symbol & Description \\
\hline & communication management \\
\end{tabular}

Stereotypes for activities were used as a solution to integrate communication management modelling with processes. Such integration of communication management was possible for BPMS by assigning correct symbols to the activity objects. In this way the dedicated, ascribed icons fulfil the role of stereotypes for activity objects, thus extending their meaning. Such an approach permitted both the integration of communication management modelling with the models of processes and the quick reference in locating detailed communication coordination diagrams connected with particular processes. Figure 1 presents an example of such integration for the process called Production of an e-learning course. The integration of communication management stereotypes also allows for verification as to whether there is the correct number of activities and that these activities contain actions to ensure proper communication between significant numbers of parties participating during this process.

\footnotetext{
${ }^{1}$ Modelling notation was elaborated for all management categories included in Table 1, yet the paper concentrates only on communication management modelling as justified in the first section.
} 


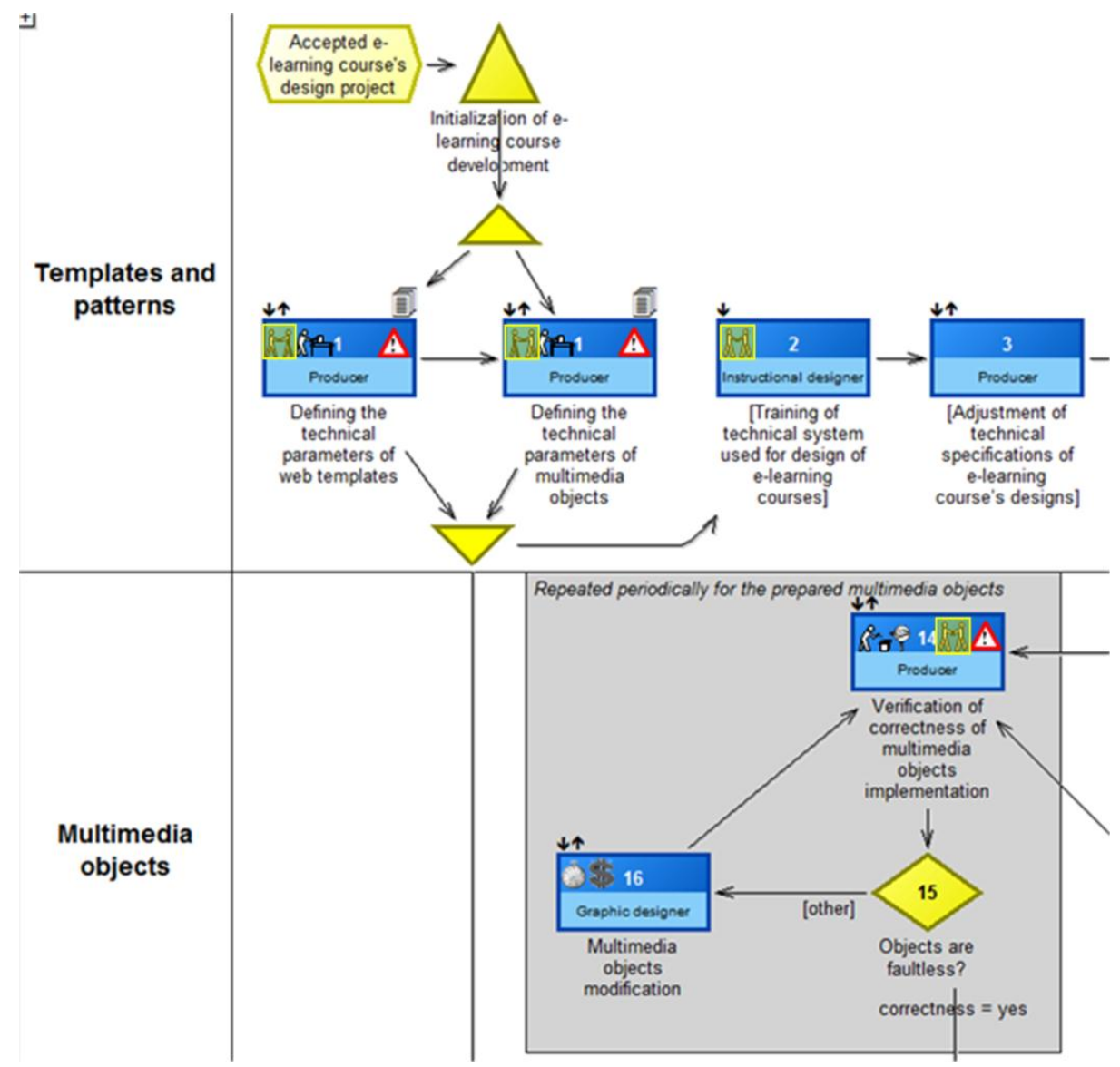

Fig. 1. Process model with integrated communication management - Production of an e-learning course.

In the example diagram above, activities distinguished as strongly related to communication management are as follows: Defining the technical parameters of web templates, Defining the technical parameters of multimedia objects, Training of a technical system used to design e-learning courses and Verification of correctness of multimedia objects implementation. Such a modelling approach forces proper thinking about communication when the processes are carried out and has a positive impact on the quality of implementation of these processes. Thus, an elaborated communication management notation indirectly supports quality-oriented modelling of processes [14].

The modelling approach used for the integration of communication management with the specifications of processes was also used for other important project management categories, such as risk, quality, resources or document flow. This developed notation was based exclusively on the author's experience and interviews with project managers. As a new concept it required appropriate verification, which is 
presented in the third section of the article. Communication management modelling is based on dedicated diagrams consisting of visual notation elements as described in Table 2 .

Table 2. Notation for Communication Management Modelling of Processes

$\begin{array}{ll}\text { Activity } & \begin{array}{l}\text { Description } \\ \text { Activity related to communication management and the } \\ \text { business or project process model. }\end{array} \\ \text { Person responsible for the actions of communication } \\ \text { management within the framework of the activity. }\end{array}$

This elaborated modelling notation was used to develop a complex, integrated project management model for the production and implementation of e-learning courses as a case study example. A sample communication management diagram elaborated with the help of developed notation for the process of the Production of an e-learning course is presented in Fig. 2. Communication management in this process is mainly connected with activities related to defining development parameters and the verification of results. Thus, communication management in the process of the Production of an e-learning course refers to activities such as Defining the technical parameters of web templates or Defining the technical parameters of multimedia objects. The aim of these activities is to provide sufficient specification that will determine how, from a technical perspective, to carry out component production and to ensure effective cooperation of many parties carrying out the development process. It is also an important aspect of quality management for the process [16].

Each activity with distinguished communication management has at least one identified communication form, such as project meeting $(s)$ or synchronous/asynchronous online meetings as presented in Fig. 2. For activities that are performed in parallel (have the same sequence number in Fig. 1), communication management can often be specified collectively as shown in Fig. 2. 


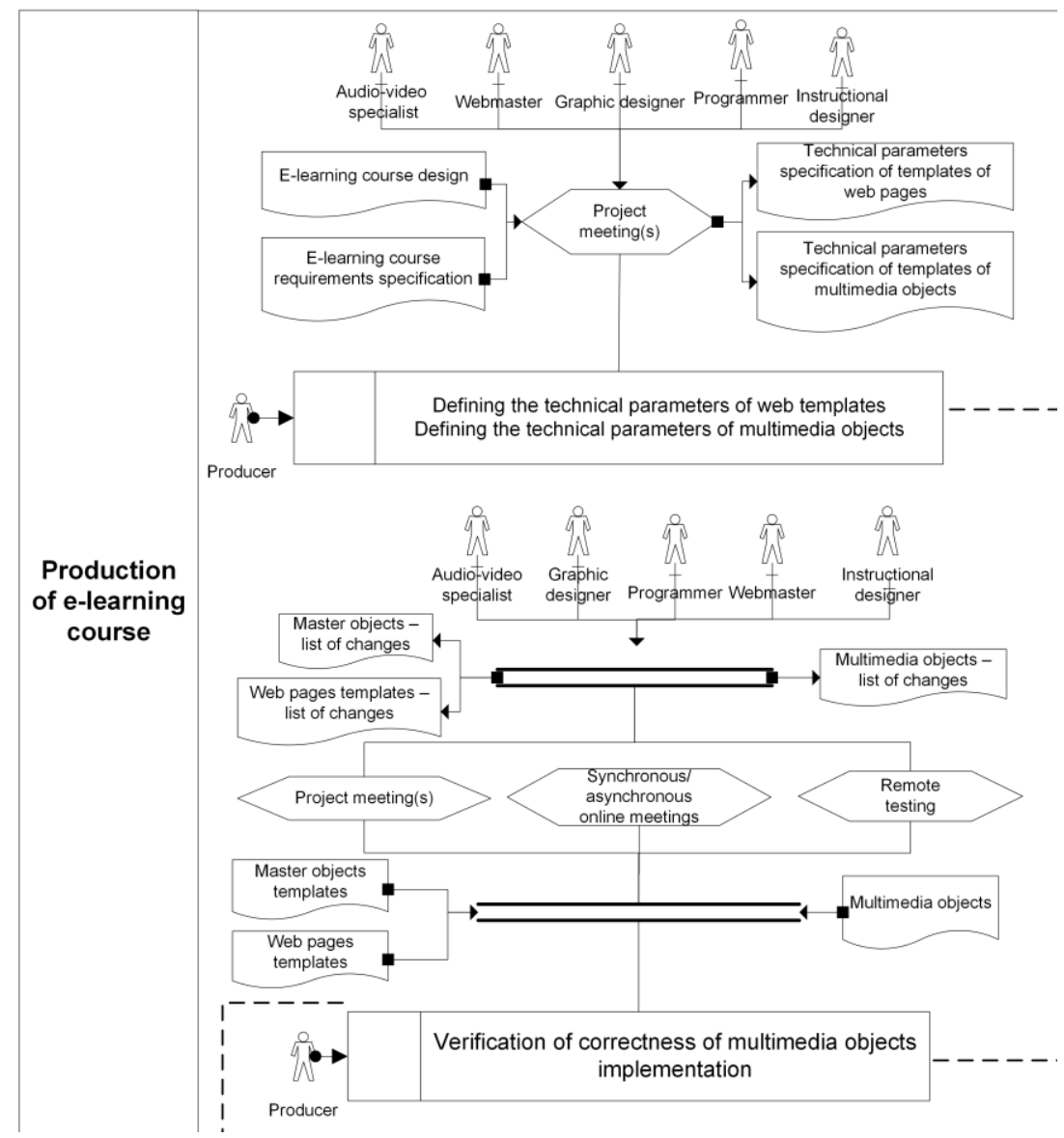

Fig. 2. Communication management diagram for the process of Production of an e-learning course.

Input elements were identified as documents to be reviewed or consulted for each communication form. Activities highlighted and dedicated to communication management in Fig. 2 are, e.g., E-learning course design or E-learning course requirements specification. Also, communication forms usually representing particular types of meetings are accompanied by results, such as Multimedia objects list of changes. Such a requirement in the proposed modelling approach of communication management for processes is very important because it forces us to obtain the direct results of face-to-face or online meetings. If outcomes cannot be specified, it usually means that communication management for the process activity is unnecessary.

Appropriate communication management diagrams were elaborated for all processes outlined for the development of the e-learning course as a case study example: requirements analysis, elaboration of scripts, instructional design, production, evaluation and implementation, and evaluation and revision (periodical). 
The presented, elaborated notation allows developing diagrams that visualize, in a complex manner, concepts related to communication management for a sequence of activities identified on the process flow diagrams. Although such a way of integrating communication management stereotypes with the activities of processes and pointing out appropriate types of communication for them may look trivial, it is nevertheless very important in order to carry out processes appropriately. Such a modelling approach stimulates the verification of the activities of processes and identifies whether there is sufficient communication management. It also forces reflection as to the forms of communication and the parties between which they should be planned.

\section{Evaluation of an Elaborated Communication Management Modelling Approach for Processes}

It was only possible to prove the usability of an elaborated modelling approach of communication management for processes by implementing it for process specification of real-world projects. Such an approach was carried out to develop a model for managing e-learning projects. The elaborated model was used to develop 16 courses during two projects:

- The Implementation of Modern Education Elements at the University of Gdansk (2008-2010);

- Catching the Future (2011-2012).

The aim of the both projects was to develop and implement e-learning courses in a way that was similar to software engineering. It is important to emphasize that different project management methodologies were used in the listed projects. Within the framework of the project "The Implementation of Modern Education Elements at the University of Gdansk", the traditional, cascade approach was used. The initiative "Catching the Future" was carried out based on an agile methodology and RID (Rapid Instructional Design). The primary RID objective is to reduce the time needed for the design, production and implementation of e-learning courses while maintaining the high quality of final product [19]. Such an approach requires extremely efficient communication management when the activities are carried out [22], [23].

The developed project management model with an elaborate communication management notation was applied when these different projects were carried out. Simultaneously as these projects were run, adaptation to the requirements of communication management was monitored, especially from the perspective of completeness of the developed modelling notation and process specifications. It turned out that neither additional notation elements nor modifications were necessary for communication management model of the processes. The users of the model, such as project managers, instructional designers and producers, emphasized that the diagrams dedicated to communication management were easy to understand and very practical to use when the processes were carried out. This indicated the completeness of the elaborated communication management modelling approach and its usability for the specifications of processes. 
Additionally, within the framework of the project "The Implementation of Modern Education Elements at the University of Gdansk (2008-2010)", the developed communication, quality and risk modelling approach was verified in terms of having an effect on the efficiency of process execution. Verification was conducted for six projects of e-learning courses developed and implemented at the University of Gdansk between 2008 and 2010. For four projects, management was based on the elaborated modelling notation as presented in the second section of this paper. The other two projects were established based on the project manager's experience and the general project management model developed by the PEUG organization (Educational Portal of University of Gdansk). Verification showed that in projects carried out without the use of a developed model with integrated communication, quality and risk management:

- there were serious deviations between execution of some of the processes, such as design and production and their schedules,

- many multimedia objects were of inadequate quality to meet the requirements.

The direct effect was the need to partially re-execute processes, such as design, production and implementation of e-learning courses. A detailed analysis revealed that the main reasons for the failure of project were connected with incorrect communication, risk and quality management. From a communication management perspective, this was related to a lack of specifications for:

- substantial consultations when designing the multimedia objects,

- compliance evaluation of a list of planned multimedia objects with their initial concepts.

This caused many faults even on the specification level of the e-learning courses. It was also the reason for the choice of inappropriate script parts for multimedia adaptation according to the authors' requirements. This led to the need for the development of additional multimedia objects with a different instructional design approach. Furthermore, the actions related to communication management, such as verification of implementation of multimedia objects and their conformity with the projects, were not carried out in a complex manner - they only had the form of a general check of specification completeness without proper consultations with the authors. Together with the design process faults, this caused the preparation of many low quality multimedia and learning objects with a number of serious errors.

Alternatively, e-learning course projects carried out with the use of an elaborated modelling approach with a strong accent on communication management specification had only minor deviations from the schedule. Also, the quality of components building up the final products as e-learning courses was highly assessed with a need to make only a few modifications.

The conducted model verification supports the opinion that the use of elaborate communication management notation allows for processes to be carried out better and according to schedules; it limits the number of errors committed during various processes and helps to increase the quality of the end products, as in the case study of e-learning courses. Also, the research results show that the use of an elaborated approach enables better implementation of business and project processes thanks to focusing on: 
- integration of communication management at the level of activities and not only at the general level,

- stimulating communication management integration for processes in the field of distinguishing missing activities dedicated to communication management.

\section{Conclusion}

The present study has showed the concept of communication management modelling of processes. As a starting point, a review of modelling notations and systems has been offered with an outline of their weaknesses. The analysis has shown that none of the modelling approaches analyse as BPMN, and their weaknesses for designing communication in business or project processes have also been considered.

The original modelling notation in this field has been proposed in the second section of the article. An elaborate notation has been used in the modelling processes for project management, but its general form also allows applying it for business processes. One of the key factors is the appropriate integration of communication management with processes, which is achieved by using stereotypes for activity objects. An elaborate and integrated modelling approach has enabled the development of a communication management model to manage the processes of e-learning projects as a case study.

The article has concluded with the assessment of a communication management notation for documenting processes. Verification has included the evaluation of the completeness of an elaborate notation when two projects were carried out. Also, its usability for the development of project management models that support the proper implementation of projects according to schedules has been analysed. The results of the research have confirmed that the use of models based on an elaborate modelling notation allows for better implementation of processes according to their schedules and helps to increase the quality of end products. In this manner, it supports higher efficiency of managing projects and business processes.

\section{References}

1. Ambler W., The Elements of UML 2.0 Style, Cambridge University Press, Cambridge (2005) http://dx.doi.org/10.1017/СB09780511817533

2. Baca C., Project Manager's Spotlight on Change Management, Sybex, Almeda (2005)

3. Decker G., Barros A., Interaction Modelling using BPMN, Hofstede A., Benatallah B., Paik H. (eds.) Business Process Management Workshops, LCNS 4928, Springer-Verlag Berlin Heidleberg (2007)

4. Eriksson H., Penker M., Business Modelling with UML: Business Patterns at Work, Wiley, New York (2000)

5. Eriksson H., Penker M., Lyons B., Fado D., UML 2 Toolkit, OMG Press, Indianapolis (2004)

6. Harrison-Broninski K., The Future of BPM. Part 2, 
http://www. bptrends.com/publicationfiles/09-06-ART-FutureBPM20f6-Harrison-Broninski.pdf

7. Hoyer V., Bucherer E., Schnabel F., Collaborative e-Business Process Modelling: Transforming Private EPC to Public BPMN Business Process Models, Hofstede A., Benatallah B., Paik H. (eds.) Business Process Management Workshops, LCNS 4928, Springer-Verlag Berlin Heidleberg (2007)

8. http://racichart.org

9. http://www.it-cortex.com/Stat_Failure_Cause.htm The Bull Survey (1998)

10. http://www.omg.org/spec/BPMN/2.0/PDF

11. http://www.omg.org/spec/BPMN/2.0/examples/PDF

12. Jiafeng L., Beiping L., Li F., Study of Unified Communications Platform Application for the Enterprise, Qian Z., Cao L., Su W., Wang T., Yang H. (eds), Recent Advances in Computer Science and Information Engineering, LNEE 127, Springer-Verlag Berlin Heidleberg (2012)

13. Kalnins A., Barzdins J., Podnieks K., Modelling Languages and Tools: State of the Art, Proceedings of 2nd International Conference on Simulation, Gaming, Training and Business Process Reengineering, (2000)

14. Kuciapski M., Improving Efficiency of Managing Projects by Quality-Oriented Modelling of Processes, 21st International Conference on Information Systems Development, ISD2012, Springer monograph in progress, Prato (2012)

15. Kuciapski M., Marcinkowski B., A Business Process Modelling Notation Extension for Risk Handling, 11th IFIP TC 8 International Conference on Computer Information Systems and Industrial Management, CISIM, Venice 2012, Lecture Notes in Computer Science, Springer Volume 7564 (2012)

16. Kuciapski M., Model for Project Management for Development and Implementation of ELearning Courses, Forbig P., Gunther H., Perspectives in Business Informatics Research, Proceedings of 9th International Conference, BIR 2010, Springer, Rostock (2010)

17. Kuciapski M., Risk Management in E-learning Projects of Courses Development and Implementation, Studies and Materials of Polish Society of Knowledge Management, Congress of Young Scientists, ISBN 978-83-7518-245-3, Międzyzdroje (2010)

18. Magnani M., Montesi D., BPDMN: A Conservative Extension of BPMN with Enhanced Data Representation Capabilities. In: Proceedings of CoRR (2009)

19. McVay Lynch M., Roecker J., Project Managing E-Learning: A Handbook for Successful Design, Delivery and Management, Routledge, New York (2007)

20. Nicholas J. M., Project Management for Business and Engineering Second Edition, Elsevier Butterworth-Heineman, Oxford (2004)

21. Pavalkis S., Nemuraite L., Mileviciene E., Towards Traceability Metamodel for Business Processes Modelling Notation, Skersys T., Bulteris R., Nemuraite R., Suomi R. (eds.) Building the e-World Ecosystem, Springer, International Federation on Information Processing (2011)

22. Piskurich G., Rapid Training Development: Developing Training Courses Fast and Right, Pfeiffer, San Francisco (2009)

23. Piskurich G., Rapid Instructional Design: Learning ID Fast and Right, Pfeiffer, San Francisco (2006)

24. Termini M. J, From Concept to Customer: Portfolio, Pipeline, and Strategic Project Management, Society of Manufacturing Engineers, Dearborn (2009)

25. van der Aalst W. M. P., Formalization and Verification of Event-driven Process Chains, http://citeseer.ist.psu.edu/viewdoc/summary?doi=10.1.1.33.1015 
26. Vom Brocke J., Rosemann M., Handbook on Business Process Management 2, Strategic Alignment, Governance, People and Culture, Springer-Verlag Berlin Heidleberg (2010) http://dx.doi.org/10.1007/978-3-642-01982-1

27. Yeon Y., Jung J., Cho N., Kim H., Kang S., Integrated Process Modelling for Dynamic B2B Collaboration , Khosla R., Howlett R., Jain L. (eds.) Knowledge-Based Intelligent Information and Engineering Systems, LNAI 3683, Springer-Verlag Berlin Heidleberg (2005)

28. Zor S., Schumm D., Leymann F., A Proposal of BPMN Extensions for the Manufacturing Domain. In: Proceedings of 44th CIRP International Conference on Manufacturing Systems (2011) 